\title{
Frass drop for monitoring relative abundance of large arboreal invertebrates in a New Zealand mixed beech forest
}

\author{
Peter Sweetapple* and Mandy Barron \\ Landcare Research, PO Box 69040, Lincoln 7640, New Zealand \\ *Author for correspondence (Email: sweetapplep@LandcareResearch.co.nz)
}

Published online: 3 June 2016

\begin{abstract}
Biodiversity managers need robust and cost-effective tools to monitor ecosystem health and outcomes of management actions. Large arboreal invertebrates are important components of forest ecosystem food webs, but can be difficult and expensive to monitor because of their inaccessibility. Frass drop has been used extensively in Europe and North America to index the abundance of arboreal invertebrates, but has rarely been used in an ecological context in New Zealand. We assessed the practicality of, and developed protocols for, the frass-drop method to monitor the abundance of tree weta (Hemideina crassidens), stick insects (Phasmatodea) and molluscs (Mollusca) under three tree species at two sites within a New Zealand native forest. Raw material costs for litter trays were low (\$NZ 16.60 per tray) and frass (faecal material) of all three groups was distinctive and could be easily and quickly extracted from litter samples by manual sorting. Stick insect frass drop weight varied by one to two orders of magnitude between tree species and site (21-95\% occurrence), but tree weta and molluscs frass was common (65-90\% occurrence) under all tree species at both sites. Within site spatial variation in frass drop was large and dominated by differences between sample trays, regardless of tree species. Sampling using clusters of three trays as sampling units was more efficient than single-tray sampling at achieving target levels of power for simple site-mean indices of abundance. The method has several advantages over other low-cost methods that are currently used, but requires further validation of the relationship between frass drop and invertebrate abundance in a New Zealand context.
\end{abstract}

Keywords: abundance monitoring; arboreal invertebrates; frass drop; molluscs; stick insects; tree weta

\section{Introduction}

Practical, robust and cost-effective monitoring tools are key to the successful management of natural ecosystems. Monitoring allows managers to assess the need for and success of management actions such as animal pest or weed control. Arboreal invertebrates are important components of forest ecosystems but because of their inaccessibility can be difficult to monitor, with many of the established methods such as fogging with insecticide, branch clipping, canopy malaise traps and systematic searches (Southwood 1978; Stork et al. 1997; Rufaut \& Gibbs 2003; Watts et al. 2008; Eymann et al. 2010) time consuming.

Many large invertebrates are particularly vulnerable to predation from invasive small mammals, especially rats (Rattus species; Bell 1978; Towns 2009; St Clair 2011; Ruscoe et al. 2013). The tree-climbing ability and ubiquity of predatory ship rats (R. rattus; Innes 2005; Foster et al. 2011) and stoats (Mustela erminea; King \& Murphy 2005) and occasionally omnivorous possums (Trichosurus Vulpecula; Cowan 2005) mean that populations of large arboreal invertebrates are potentially at risk of predation-induced decline throughout New Zealand forests. However, tree weta (Hemideina species) are the only arboreal invertebrates that are routinely monitored in New Zealand (e.g. Rufaut \& Gibbs 2003; Spurr \& Berben 2004; Watts et al. 2011).

Low cost methods for monitoring tree weta have been developed and include occupancy of artificial tree cavity roosts (weta motels; Trewick \& Morgan-Richards 2000; Bleakley et al. 2006), capture rate in lethal pitfall traps, and tracking rate in footprint tracking tunnels (Watts et al. 2011). These methods have their advantages and disadvantages (see Watts et al. 2011), but all require tree weta to interact with artificial devices placed near to or on the ground, potentially introducing biases given that tree weta change activity patterns following pest control (Rufaut \& Gibbs 2003). Weta motels also have the disadvantage that occupancy rates take up to 1-3 years to stabilise after they are installed in the field (Trewick \& Morgan-Richards 2000; Spurr \& Berben 2004; Bleakley et al. 2006; Ruscoe et al. 2013).

Quantifying the fall of invertebrate faecal material from tree canopies (frass drop) has long been used globally as a useful and cost effective index of the abundance of canopy dwelling invertebrates (Morris 1949; Liebhold \& Elkinton 1988a, b; Kamata et al. 1994; Fischbacher et al. 1998; Mizutani \& Hijii 2001). The method is rarely used in New Zealand, but has been used to monitor weta abundance trends in Northland (reported in Veltman 2000) and has been correlated with adult giant weta (Deinacrida heteracantha) abundance (C. Watts pers. comm.). European earwig (Forticula auricularia) frass collections in artificial refuges have also been correlated to the number of earwigs in refugia and predation rates on lightbrown apple moth (Epiphyas postvittana) eggs in apple trees (Suckling et al. 2006). Therefore, frass drop collection is potentially a practical alternative for monitoring tree weta populations and may simultaneously monitor a range of other arboreal invertebrates. However a similar method, quantifying egg drop, has been investigated for New Zealand stick insects (Phasmatodea) but was found to be unrelated to stick insect abundance (I. Stringer, NZ Department of Conservation, pers. comm.).

Large arboreal invertebrate such as tree weta, stick insects and slugs (Gastropoda) are common dietary items of ship rats in New Zealand forests (Best 1969; Daniel 1973; Miller 
\& Miller 1995; Blackwell 2000) and sometimes respond positively to rat control (Towns 2009; Watts et al. 2011; Ruscoe et al. 2013). Some of these, in addition to tree weta, may therefore provide useful targets for assessing biodiversity outcomes of pest control. As part of a larger study to investigate outcomes of pest control, we extracted frass of tree weta, stick insects and molluscs along with stick insect eggs from litter samples collected over a 4-year period in two mixed beech (Nothofagaceae) forests. Our main objective for this work was to develop sampling and processing protocols for, and assess the practicality of, the frass drop method for three invertebrate groups and egg drop for one group in a New Zealand context. The impact of pest control on arboreal invertebrate abundance at the study sites will be briefly discussed here and reported in detail elsewhere.

\section{Methods}

\section{Study sites}

Two sites in the Tararua Forest Park, southern North Island, New Zealand, were chosen for the study. One site, Totara Flats, was located in the Waiohine catchment on the eastern side of the Tararua Range ( $40^{\circ} 56^{\prime}$ South, $175^{\circ} 20^{\prime}$ East) and the other, Waitewaewae, was in the Otaki catchment, immediately north of the Otaki-Waitewaewae confluence $\left(40^{\circ} 48^{\prime}\right.$ South, $175^{\circ} 20^{\prime}$ East) on the western side of the Tararua Range. Both sites were on river terraces and hill toe slopes, adjacent to the main water courses. Forests were mixed beech-podocarp-hardwood associations with canopies principally comprised of red beech (Fuscospora fusca), silver beech (Lophozonia menziesii), tawa (Beilschmiedia tawa), kāmahi (Weinmannia racemose) and hīnau (Elaeocarpus dentatus). Scattered emergent rimu (Dacrydium cupressinum) and other podocarps were common. However, canopies in the wetter and more elevated (320-400 $\mathrm{m}$ a.s.1.) Waitewaewae site were dominated by red and silver beech, while those at Totara Flats (200-300 m a.s.1.) were dominated by tawa, hīnau, and kāmahi (unpublished data).

It is likely that the study area contains only one species of tree weta (the Wellington tree weta; Hemideina crassidens), although isolated populations of the Auckland tree weta (Hemideina thoracica) are present about $10 \mathrm{~km}$ to the west of the Waitewaewae site (Trewick \& Morgan-Richards 1995). At least four species of stick insect occur in the study area (see results), but little is known about arboreal molluscs in the area.

\section{Sampling design}

A single $5 \mathrm{~km}$ long transect was established at both sites in August 2010. It started $2.5 \mathrm{~km}$ within pest controlled areas (aerially delivered 1080 toxin in October 2010 and December 2013) and ended $2.5 \mathrm{~km}$ outside the controlled areas. Data from only those parts of the transects that were at least $500 \mathrm{~m}$ away from the pest-controlled areas were used in the current study. Within these $2 \mathrm{~km}$ transect sections, sampling stations were located every $200 \mathrm{~m}$ along both transects (10 points per site), where one tree exceeding $10 \mathrm{~cm}$ diameter at $1.4 \mathrm{~m}$ above ground of each of the three target species (rimu, kāmahi, toro (Myrsine toro)) was selected (30 trees per site). Tree species were chosen to include two species with possum-palatable foliage (kāmahi and toro) and one without (rimu) to satisfy other study objectives. Sampled trees were subjectively chosen to minimise stem lean and intermingling of crowns with adjacent trees.
A litter tray was placed against the northern side of selected trees and was mounted on wooden stakes about $1 \mathrm{~m}$ above the ground in November 2010. Litter trays were $60 \mathrm{~cm}$ in diameter $\left(0.28 \mathrm{~m}^{2}\right.$ catching area) and constructed of $1.1 \mathrm{~mm}$ mesh fibreglass fly-screen (Cyclone Tools Ltd, Dandenong South, Australia) funnels hung from $4 \mathrm{~mm}$ mild-tensile wire (No. 8 wire; Cyclone Wire, Fletcher EasySteel, Auckland) hoops, with the base of the funnel tied closed (Fig. 1). Trays were emptied in November and their contents collected in February, from November 2010 until February 2014. All February collected samples were sorted, giving a total of 240 sorted samples.

\section{Frass sorting procedure}

Litter samples were stored frozen until sorted. Samples were air dried then shaken through stacked $10 \mathrm{~mm}, 2 \mathrm{~mm}$ and $0.355 \mathrm{~mm}$ mesh sieves. Material retained in the $10 \mathrm{~mm}$ mesh (predominantly foliage) was checked for frass but none was found. Material that passed through the smallest mesh was discarded. All tree weta, stick insect and mollusc faecal material, and stick insect eggs were extracted from the material retained by the $2 \mathrm{~mm}$ mesh. All material retained in the $0.355 \mathrm{~mm}$ mesh $($ mean $=3.38 \mathrm{~g}$ ) was sorted when $<1.5$ $\mathrm{g}$ was present. When more than $1.5 \mathrm{~g}$ was present $(93 \%$ of samples) it was sub-sampled to select $0.75-1.5 \mathrm{~g}$ of material $($ mean $=1.04 \mathrm{~g})$ for sorting under a low powered stereoscope $(6.4 \times$ magnification). Subsampling was conducted by sweeping the $0.355 \mathrm{~mm}$ retained material into a symmetrical pile then dividing it into two visually equal parts and discarding one part. This was repeated up to three times as required. The three faecal material categories (above) and stick insect eggs were extracted from the $0.355 \mathrm{~mm}$ subsample material. Identification

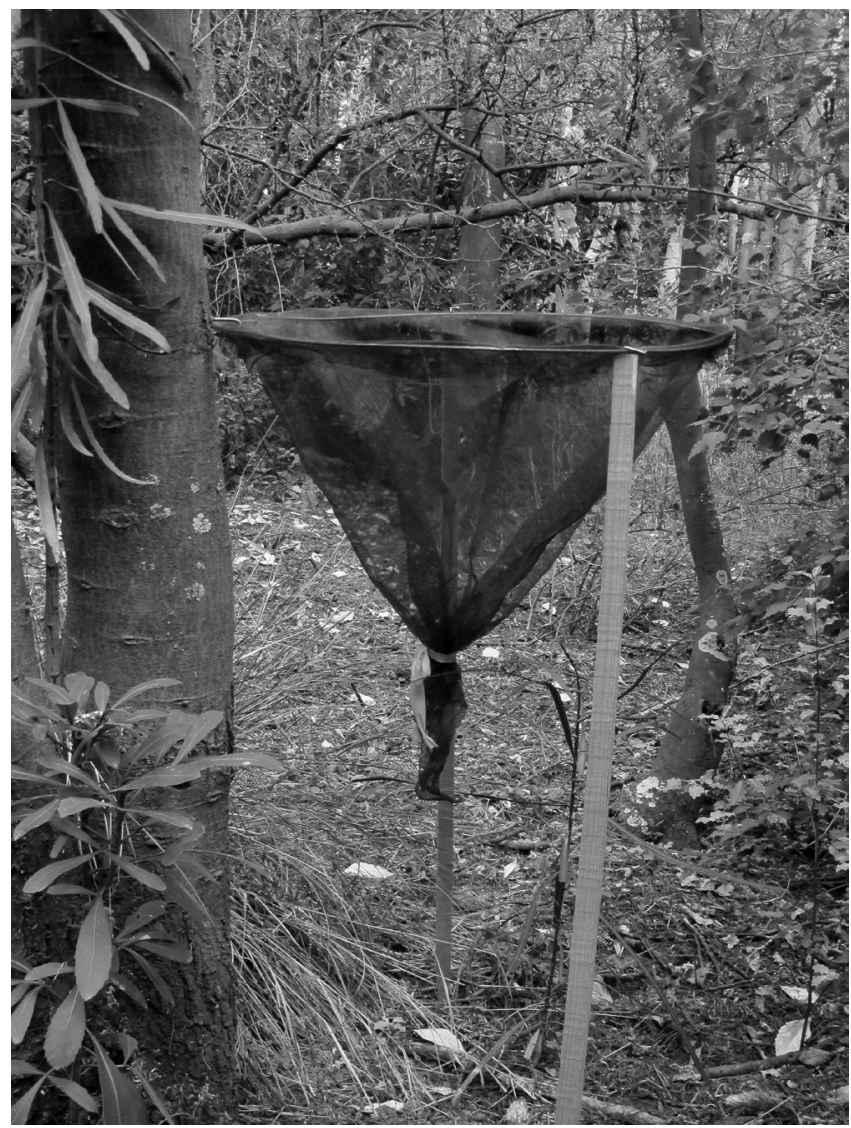

Figure 1. Litter tray used for collecting frass drop samples at two study sites in the Tararua Range between 2010 and 2014. 
of faecal material was aided by comparison with material collected over 24 hours from one wild-caught adult stick insect (Acanthoxyla geisovii), one male and one female wild-caught adult Auckland tree weta (Hemideina thoracica), and material collected from nearby weta motels occupied by slugs. Stick insect eggs were identified to species from photographs at www. landcareresearch.co.nz/science/plants-animals-fungi/animals/ invertebrates/systematics/phasmatodea (accessed 1/12/2011).

Tree weta faecal pellets and stick insect eggs were counted. Stick insect and mollusc faecal pellets were not counted as they were sometimes fragile and broken. All extracted faecal material was oven dried at $70^{\circ} \mathrm{C}$ for 24 hours and weighed to the nearest milligram. We estimated the mean weight of individual stick insect and mollusc faecal pellets using 100 intact pellets of each kind randomly selected from samples from both sites. Weights of the total sample, material retained in the $2 \mathrm{~mm}$ and $0.355 \mathrm{~mm}$ mesh-sieves, and material that passed through the $0.355 \mathrm{~mm}$ mesh were also recorded during this trial.

\section{Data analysis}

Dry weights of frass, and numbers of faecal pellet for tree weta, were adjusted for the proportion of the $0.355 \mathrm{~mm}$ mesh retained material that was subsampled, then were examined for distribution and abundance patterns in frass drop among the two sites and three tree species to assess the importance of tray location to sampling design. Data were modelled using a generalised linear mixed model (GLMM) with a log link, a random effect for each tray since trays were measured in multiple years from the same location (2011-2014), and an observation-level (tray $\times$ year) random effect to account for overdispersion in the data (in this case an excess of zero weights).

We partitioned the sources of variation in frass drop weights into different levels (site, tree species, litter tray, observation) using GLMM for individual tray measurements (Nakagawa \& Schielzeth 2010). For each invertebrate group, frass drop weight $(\mathrm{mg})$ or number of pellets per trap per observation was regressed against the random effects of site, trap (nested within site), and observation (nested within trap) with a crossed tree species random effect. We assumed a log link for the response scale and Poisson-distributed variance, however including an observation-level random effect allows for additive overdispersion and thus extra-Poisson variation.

Fewer, larger samples will reduce total sorting time (see discussion), while potentially reducing sample variance. Therefore, we pooled data from the three trays at each sampling station to simulate using a cluster of three trays as the basic sampling unit to produce a site-average index of arboreal invertebrates and compared the variance of frass drop estimates between three-tray and single-tray samples. Therefore, pooled data was from three different tree species. This reflects the spatial layout of litter trays (three trays clustered at sampling stations) rather than any biological rationale for pooling data from different tree species, but it provides a simple site-average index of invertebrate abundance comparable to that from single trays (same three species sampled at each sampling station for both sampling strategies). The efficiency of the two sampling strategies was compared by calculating the sample sizes needed to obtain $80 \%$ power to detect a difference between site means for two effect sizes (a 50\% or 100\% change in mean weight or number per site). The power analysis was done by fitting a GLMM as above to the data on the weight or number of frass pellets, except we fitted site and tree species as fixed effects with the random effects of individual trays and observations as before. For the pooled (three-tray) analysis, station replaced tray
ID as the random effect and since stations always comprised one of each of the three tree species, the fixed effect of tree species was dropped. The fitted intercept, random effects and residual errors and a notional site effect, which was set to give a $50 \%$ or $100 \%$ increase in the raw response (weight or number or frass pellets), were together used to generate multiple sets $(n=1000)$ of new simulated data (using simulate.merMod in the lme4 package). A mixed effects model with the same structure as the original was then fitted to each dummy data set and the proportion of the thousand refitted models that identified a site effect (assessed by a 95\% confidence interval on the coefficient not including zero) was used as the power estimate. This process was repeated over a range of sample sizes to identify the sample size where the ability to detect a site effect exceeded $80 \%$.

Analyses were performed using version 3.22 of the $\mathrm{R}$ statistical platform (R Development Core Team 2015).

\section{Results}

\section{Faecal material descriptions}

Tree weta, stick insects and molluscs all produced distinctive, readily identifiable faecal pellets. Tree weta produce stout, cylindrical pellets with a length-to-width ratio of about 2, up to $6 \times 12 \mathrm{~mm}$ in size $(0.067 \mathrm{~g}$ mean dry weight, $\mathrm{n}=1211)$ with a smooth black or brown surface. Most pellets have 12 longitudinal surface bands of alternating dark and lighter coloured material and are typically slightly curved, with one rounded end and one flattened or concave end (Fig 2a). As pellets age and deteriorate the smooth surface and coloured bands are lost, typically revealing coarse foliar fragments, with the colour fading to a light brown or grey. The majority of pellets comprised mainly foliage but many also contained seed and invertebrate material; occasionally pellets consisted entirely of invertebrate remains. They are most easily distinguished from rodent faecal pellets by the presence of the obvious foliar fragments and the absence of rodent hair. Additionally, rodent faecal pellets are typically black, regardless of age, narrower than those of tree weta, and rounded or tapered at both ends.

Stick insect faecal pellets are narrow, rough, straight cylinders up to $1-1.5 \times 4-5 \mathrm{~mm}$ in size $(0.004 \mathrm{~g}$ mean dry weight, $n=100$ ) (Fig. 2b). They are variable in colour depending on their contents, ranging from pale green to dark red-brown. The surface texture is always rough, reflecting the coarse foliar contents. Fresh pellets are covered in a thin mucus cuticle (skin) that does not conceal the pellets' contents, but this disappears with weathering. Pellets become fragile as they weather. Similar sized and shaped pellets are produced by at least one other unidentified arboreal invertebrate that feeds on wood, but these are distinguished from stick insect pellets by the obvious presence of wood fibres.

Mollusc faecal material extracted from litter trays was variable in size and shape, but also exhibited distinctive features. Pellets were typically black, long, thin and 'ropey', up to about $10 \mathrm{~mm}$ long (0.009 g mean dry weight, $\mathrm{n}=100)$, and usually comprised strands of numerous sub-pellets $<0.5 \mathrm{~mm}$ wide (Fig. 2c). Pellets were often flattened on one side, presumably resulting from the deposition of soft, moist material on flat surfaces. As pellets aged they became progressively marked by small pale to white flecks. The majority of mollusc frass probably came from slugs because slugs up to $3 \mathrm{~cm}$ long were occasionally found in litter samples whereas snails retained in sieves rarely exceeded $5 \mathrm{~mm}$ in diameter. 

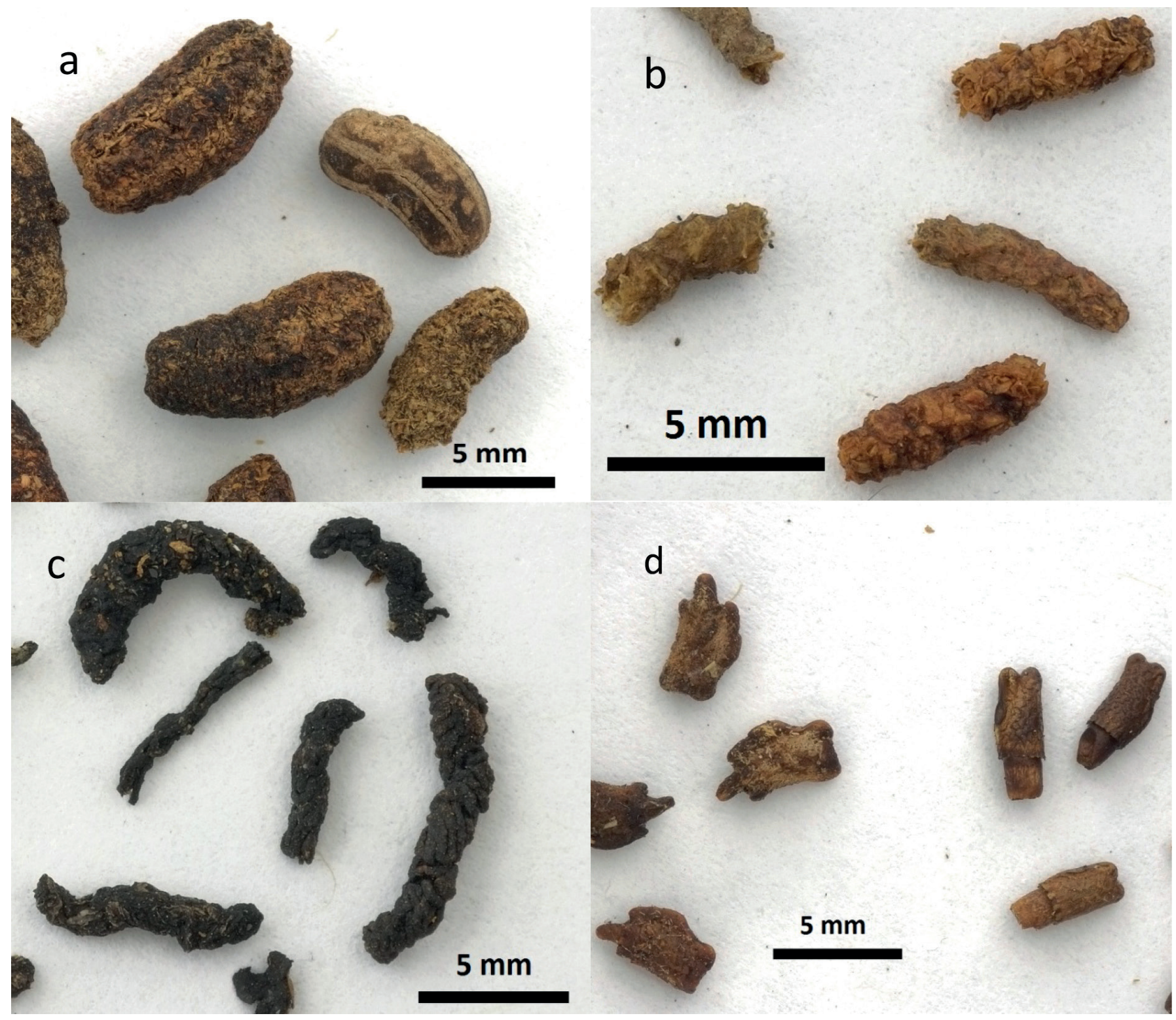

Figure 2. Faecal pellets (frass) from (a) tree weta (Hemideina crassidens), (b) stick insects (Phastmatodea), (c) molluscs, (d) eggs from stick insects and extracted from litter trays placed at two sites in the Tararua Range between November 2010 and February 2014 . Eggs on the left side of photograph (d) are from Acanthoxyla geisovii and those on the right are from Tectarchus huttoni.

\section{Sieve mesh size}

The mean total air-dried weight of 39 unsorted litter samples was $38.16 \pm 5.25 \mathrm{~g}(95 \%$ confidence limits $)$. The majority of this material $(75.6 \%)$ was retained by the $10 \mathrm{~mm}$ mesh (predominantly foliage, moss and woody material). No faecal material was found in this coarse material. Just $0.3 \%$ (mean $=0.13 \pm 0.03 \mathrm{~g}$ ) of total sample material passed through the $0.355 \mathrm{~mm}$ mesh and contained no identifiable egg or frass material. The balance of material $(24.1 \%)$, containing all identifiable frass and eggs, was split about $60 / 40$ between the $2 \mathrm{~mm}($ mean $=5.67 \pm 1.18 \mathrm{~g})$ and $0.355 \mathrm{~mm}($ mean $=3.53 \pm$ $0.61 \mathrm{~g})$ mesh sieves respectively. The majority of each frass category was extracted from one of these two sieve mesh sizes (Fig. 3). For tree weta, $97.6 \%$ of frass by weight $(85.1 \%$ of pellets) was retained by the $2 \mathrm{~mm}$ mesh while for stick insects and molluscs, $86.8 \%$ and $80.0 \%$ respectively, of frass by weight was retained in the smaller $0.355 \mathrm{~mm}$ mesh. In all cases standard errors of estimates from the mesh size retaining the most frass were similar to that for estimates of total frass (both sieves combined; Fig. 3).

Small numbers of stick insect eggs (Fig. 2d) were extracted from litter trays at Totara Flat, with a mean of 0.75 eggs $(95 \%$ $\mathrm{CL}= \pm 0.28)$ per sample from the $2.0 \mathrm{~mm}$ mesh and 0.08 eggs $(95 \% \mathrm{CL}= \pm 0.08)$ per sample from the $0.355 \mathrm{~mm}$ mesh sub-sample. Egg numbers varied in relation to stick insect frass weight, ranging from $20.0 \mathrm{~g} \mathrm{~g}^{-1}$ in 2011 to $5.6 \mathrm{~g}^{-1}$ in 2014 (Pearson correlation coefficient $r=-0.59, P=0.41, \mathrm{~N}=4$ ). At Waitewaewae only four stick insect eggs were extracted from all 120 sorted samples. Eggs were predominantly from Acanthoxyla geisovii ( $73 \%$ of all eggs) and Tectarchus huttoni (25\%) but a single egg from each of Acanthoxyla inermis and Clitarchus hookeri were found in subsamples. 


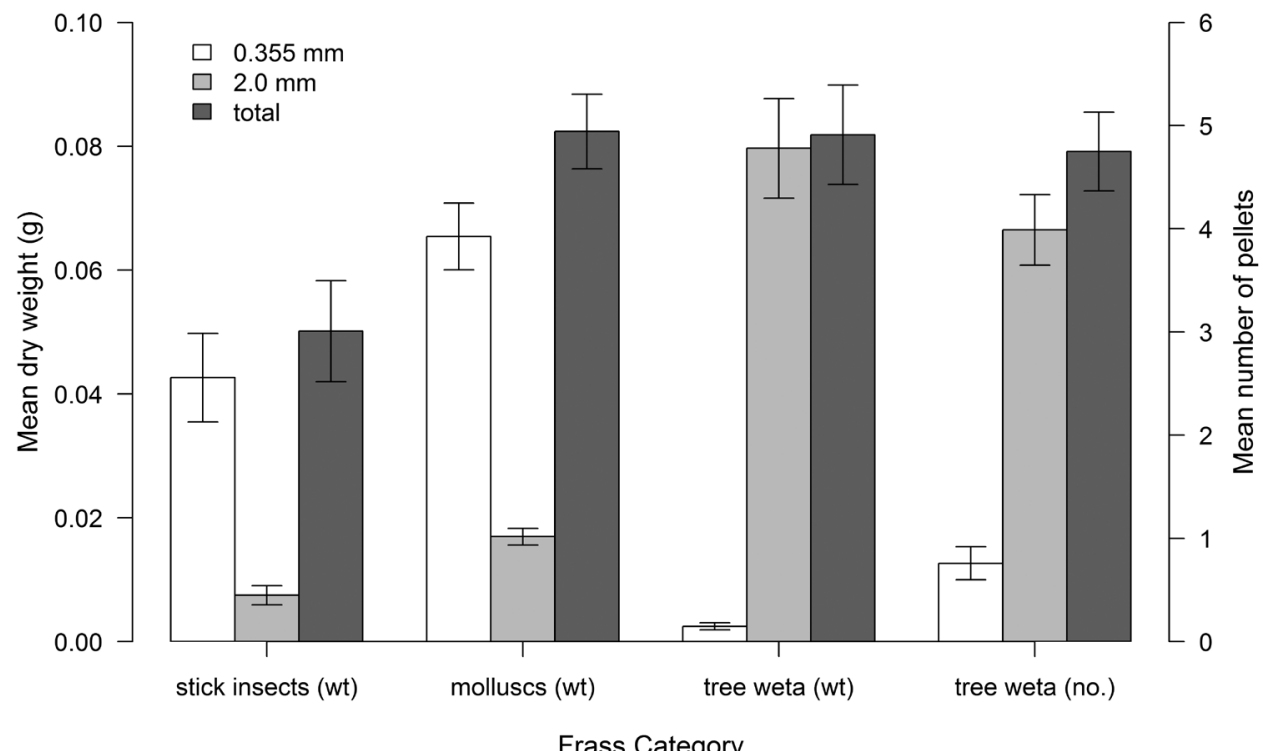

Frass Category
Figure 3. Mean $( \pm \mathrm{SE})$ dry weight (wt) and pellet number (no.) for invertebrate faecal material for three invertebrate groups retained by $0.355 \mathrm{~mm}$ mesh (white bars), $2 \mathrm{~mm}$ mesh (medium grey bars) and both (dark grey bars) sieves. Data are from 30 litter-fall trays of $0.28 \mathrm{~m}^{2}$ catching area, placed under three tree species (kāmahi, rimu, toro) at each of two sites in the Tararua Range. Sampling periods were of 3 months duration, ending each February from 2011 to 2014

\section{Sorting time}

Frass and egg retention patterns in the three sieves (above) indicated that the most efficient sorting protocol was to extract only tree weta frass and stick insect eggs retained in the 2.0 $\mathrm{mm}$ mesh, and only mollusc and stick insect frass from the $0.355 \mathrm{~mm}$ mesh sub samples. The mean time required to sort a litter sample using this simplified, streamlined protocol was $8.5( \pm 0.4 ; 95 \% \mathrm{CLs})$ minutes, ranging from 7 to 13 minutes per sample.

\section{Variation in frass drop}

Frass drop varied significantly between tree species for stick insects only and between the two study sites for stick insects and tree weta. At least six times more stick insect frass was collected under rimu than under kāmahi or toro $(Z=10.94$, $P<0.0001$ ), but only trace amounts were collected from under all trees at Waitewaewae (Waitewaewae vs. Totara Flats all trees combined: $Z=-21.38, P<0.0001$; Fig. 4). The mean frass weight for tree weta at Totara Flats was significantly more (nearly double) than at Waitewaewae $(Z=-7.79, P<$ 0.0001; Fig 4).

With the exception of stick insect frass at Waitewaewae, frequency of occurrence was high ( $\geq 65 \%$; Fig. 4) for all frass category-tree species combinations.

Variance decomposition analysis confirmed that the largest source of variation in stick insect frass drop was the study site. Tree species explained more of the variation in frass drop for stick insects than it did for tree weta and molluscs (Table 1). Variability in frass drop within a single survey (i.e. excluding site and observation session factors) was predominantly between individual litter trays, rather than between tree species, with the exception of mollusc frass drop, which was very consistent across both trays and tree species (Table 1). Unexplained variation between observation sessions (of individual trays) was the only substantial source of variation in mollusc frass drop.

\section{Pooled three-tray sampling vs single tray sampling}

Power analysis revealed that fewer samples were needed using simulated three-tray sampling stations, compared with single-tray sampling stations, to detect site differences in frass drop (Table 2). The greatest reductions in sample sizes were for dry weight of tree weta frass and stick insect frass, with c. $66 \%$ and $75 \%$ reductions respectively (Table 2 ). For mollusc frass weight and the number of tree weta faecal pellets, reductions were c. $30 \%$ and $50 \%$ respectively. However, of all the frass parameters measured the most precise (those needing

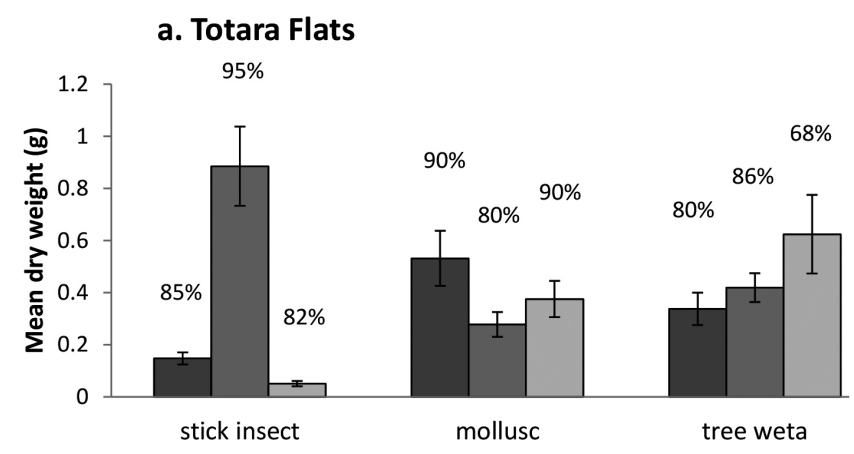

b. Waitaewaewae

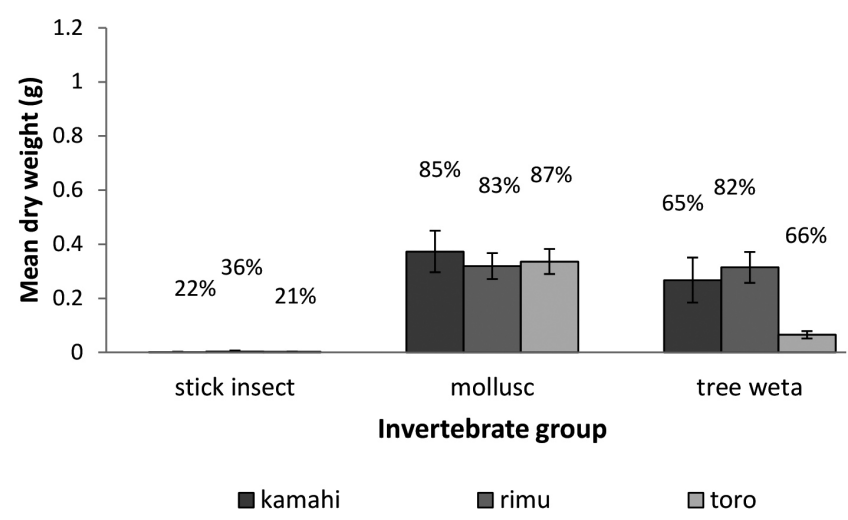

Figure 4. Raw mean dry weights $( \pm \mathrm{SE})$ of invertebrate frass extracted from 30 litter-fall trays of $0.28 \mathrm{~m}^{2}$ catching area, placed under three tree species (kāmahi, rimu, toro) at each of two sites in the Tararua Range. Sampling periods were of 3 months duration, ending each February from 2011 to 2014. The numbers above bars are percent frequency of occurrence. 
Table 1. Proportion of total variance in frass drop explained by different components of the sampling scheme from 30 litter trays placed under three tree species (kāmahi, rimu, toro) in each of two sites in the Taraua Range and monitored for three years. Variance estimates were calculated by fitting General Linear Mixed Models (GLMM) to frass weight and number of frass pellets collected in single litter-trays of $0.28 \mathrm{~m}^{2}$ catching area.

\begin{tabular}{lcccc}
\hline Variance components & $\begin{array}{c}\text { Tree weta } \\
\text { frass weight }\end{array}$ & $\begin{array}{c}\text { Tree weta number } \\
\text { of frass pellets }\end{array}$ & $\begin{array}{c}\text { Stick insect } \\
\text { frass weight }\end{array}$ & $\begin{array}{c}\text { Mollusc } \\
\text { frass weight }\end{array}$ \\
\hline Transect & 0.16 & 0.19 & 0.53 & 0.01 \\
Tree species & 0.04 & 0.01 & 0.06 & 0.00 \\
Tray ID (nested in transect) & 0.27 & 0.31 & 0.12 & 0.00 \\
Observation (nested in tray ID) & 0.51 & 0.30 & 0.25 & 0.98 \\
Poisson variance around mean & 0.01 & 0.19 & 0.04 & 0.01 \\
\hline Total variance & 6.80 & 1.96 & 12.05 & 3.56 \\
\hline
\end{tabular}

Table 2. Estimated sample sizes required to detect changes in mean invertebrate frass drop of $50 \%$ or $100 \%$, with $80 \%$ power, for single-tray and three-tray sampling stations. Data are from 30 litter-fall trays of $0.28 \mathrm{~m}^{2}$ catching area, placed under three tree species (kāmahi, rimu, toro) at each of two sites in the Tararua Range. Sampling periods were of 3-months duration, ending each February from 2011 to 2014.

\begin{tabular}{lcccc}
\hline Frass category & \multicolumn{2}{c}{$50 \%$ change in mean } & \multicolumn{2}{c}{$100 \%$ change in mean } \\
\cline { 2 - 4 } & $\begin{array}{c}\text { Single-tray } \\
\text { samples }\end{array}$ & $\begin{array}{c}\text { 3-tray samples } \\
\text { (stations) }\end{array}$ & $\begin{array}{c}\text { Single-tray } \\
\text { samples }\end{array}$ & $\begin{array}{c}\text { 3-tray samples } \\
\text { (stations) }\end{array}$ \\
\hline Mollusc (wt.) & 88 & 60 & 31 & 22 \\
Tree weta (no.) & 54 & 26 & 19 & 9 \\
Tree weta (wt.) & 194 & 48 & 70 & 16 \\
Stick insect (wt.) & 147 & 51 & 54 & 18 \\
\hline
\end{tabular}

the smallest sample sizes to meet target levels of sensitivity) was the number of tree weta pellets, with just nine three-tray samples required to detect a doubling of frass drop between surveys. This was around half the number of samples required for frass weight estimates for all three invertebrate groups (Table 2). Overall, about three times as many samples were required to detect a $50 \%$ increase in frass fall than a $100 \%$ increase (Table 2). Although both types of sampling require approximately the same number of individual trays to detect changes in frass drop, the smaller number of three-tray stations would require less time to sort (see discussion).

\section{Discussion}

Apopulation index needs to be sensitive to changes in monitored population size and practicable, including being precise enough to statistically detect biologically meaningful changes in populations with affordable sample sizes (Engeman 2005). A long history of use and analysis of invertebrate frass drop data (Morris 1949, 1960; Southwood 1978; Liebhold \& Elkington 1988a, b; Stork et al. 1997; Fischbacher et al. 1998; Mizutani \& Hijii 2001; Suckling et al. 2006) has demonstrated that this method accurately indexes arboreal invertebrate abundance for many taxa and habitats. Evidence of correlations between frass drop and invertebrate abundance from New Zealand is limited, but includes a positive correlation for adult giant weta (Deinacrida heteracantha; C. Watts pers. comm.) and a negative correlation between stick insect frass drop and ship rat abundance at our study site (unpublished data). This evidence suggests that the frass drop method has potential for monitoring arboreal invertebrate abundance in New Zealand forests, but further validation is warranted. However, our data for stick insect egg drop, and that of I. Stringer (pers. comm.), indicates that egg drop measurement may be of limited value apart for species identification.

Our study does demonstrate that the frass drop method is practical for three groups of large arboreal invertebrate in a native New Zealand forest.

\section{Practicality of measuring frass drop}

Faecal pellets of the invertebrate groups targeted in this study are relatively large and distinctive, and numerous enough in our study sites to produce robust estimates from manageable sample sizes. Therefore, minimal training of laboratory staff is required.

Using a simplified protocol, litter sample sorting took 8.5 minutes per sample on average for one experienced observer (PS). This equates to about 3 hours of sorting time to obtain frass drop estimates for all three invertebrate groups with $80 \%$ power to detect a $100 \%$ change in frass drop, using a three-tray sampling-station design. Those times extend to 8-28 hours for estimates from single tray sampling stations with $80 \%$ power to detect a $50 \%$ change in frass drop. Therefore, if a simple whole-site index of target invertebrate taxa is required, then litter sorting commitments are small to modest, depending on the power required. A comparative analysis of frass drop between tree species, forest types or other strata will require more resources.

Raw materials for litter trays are inexpensive (they cost 
\$NZ 16.60 each in November 2015) and once litter trays have been installed, field collection of samples requires little skill and minimal effort, particularly if collections are timed to coincide with other field operations.

The invertebrate groups selected for study here are common in many New Zealand forests and are common dietary items of forest dwelling rats (Innes 2005), making them potentially useful candidates for monitoring the outcomes of pest control operations.

\section{Collection and sorting protocols}

For all frass categories, most frass was retained in one of the two finest sieves used. Little or no precision was lost if material from just the one sieve that retained the greatest proportion of frass was used for mean frass estimates, compared with total frass estimates from both sieves. Therefore, the most efficient frass sorting protocol would be to extract only tree weta frass and stick insect eggs from the $2.0 \mathrm{~mm}$ sieve and extract only stick insect and mollusc frass from the finest sieve. Although too few stick insect eggs were collected to produce a robust abundance index, their extraction allows identification of the species present. Very little material passed through the finest sieve mesh we used $(0.355 \mathrm{~mm})$, suggesting that a larger meshed sieve, which would pass more fine material and reduce the amount of retained material needing sorting, could have been used.

The precision of frass drop estimates generally increases with growing frass production (Liebhold \& Elkinton 1988b; Kamata \& Igarashi 1994; Kamata et al. 1994) so sampling strategies that maximise frass catch are likely to be most efficient. Invertebrate frass production is positively linked to air temperature (Liebhold \& Elkinton 1988b; Kamata et al. 1994), with peak production occurring in summer in temperate climates (e.g. Mizutani \& Hijii 2001). Rainfall can result in the loss of frass biomass from collection trays (Kamata \& Igarashi 1994; Mizutani \& Hijii 2001). Therefore, the optimal frasssampling time in New Zealand is likely to be from January to March as mean monthly air temperatures are highest between December and March and rainfall generally lowest between January and April (NIWA 2014).

The optimal length of time for frass collection will be a trade-off between lengthy periods to maximise frass catch and reduce the effects of daily variation in temperature, versus short periods to minimise biomass loss due to rainfall. Further work will be required to determine this optimum but we suspect it will be less than the 90-day period we used, particularly if frass weights are measured. Seasonal variability in frass drop (Liebhold \& Elkinton 1988b; Mizutani \& Hijii 2001) means before and after assessments of management actions should be made over the same seasonal periods.

Previous studies found that the number of faecal pellets is more closely correlated with invertebrate density (number of individuals/unit area) than the weight of frass, because faecal pellet size is related to body size (e.g. Kamata et al. 1994). Tree weta faecal pellets were the only frass category counted during sorting and these counts had the lowest variance of all the frass categories measured. We therefore recommend that counts of tree weta pellets be made and protocols for counting faecal pellets of other invertebrates be developed. This may require shorter collection intervals than we used here. Counts have the added advantage over weights of not requiring drying and weighing, and counts will be less susceptible to biases from rainfall-induced biomass loss, as pellets can lose some biomass and still be recognised as an entire pellet. Counts in different size categories may also be useful for categorising population age structures.

Both tree weta and molluscs were relatively catholic in their distribution across the tree species monitored in this study compared with stick insects, which exhibited a strong affinity for rimu compared with kāmahi or toro. A greater range of tree species and sites than investigated here are needed to test the generality of these initial observations. If confirmed, then the most efficient sampling protocols will target specific tree species for stick insect monitoring, but will not be speciesspecific for tree weta and molluscs.

Much of the within-site variation in frass-drop for any one observation period came from variance between individual trays, regardless of tree species, presumably reflecting high tree-to-tree stochasticity in the actual abundance of tree weta and stick insects. Strategies to reduce this source of variation will improve sampling efficiency. Extracting frass from pooled multiple-tray sampling units of at least three trays appears to offers substantial cost savings over single-tray sampling. Our simulated three-tray sampling units reduced the number of samples required to attain target levels of precision by a factor of 1.5 to 4 , compared with sampling with single trays. Just nine three-tray samples were required to detect a doubling of frass drop for tree weta pellet counts (Table 2). Although three-tray sampling units required a similar number of individual litter tray placements, and thus volume of material, as single-tray sampling units, substantial cost savings are made from the reduced labour required to sort the smaller number of larger samples as most time is spent sorting the sub-sampled material from the smallest $(0.355 \mathrm{~mm})$ mesh sieve (PS pers. obs.). The larger three-tray samples can be sub-sampled in the same manner, thus require a similar time to sort as single-tray samples.

If site-level means of arboreal invertebrate abundances are all that are required for a monitoring program, then sampling could be independent of tree species. Alternatively, key tree species can be chosen, as in our study, to maximise frass catch and precision, or to investigate species-host relationships. If targeting specific tree species, multi-tray-unit sampling could be implemented by sampling clusters of conspecifics. Cautious interpretation of any tree species-specific results will be needed as all tray placements (single or multi-tray units) will be subject to mixing of litter from the target and neighbouring trees, particularly for smaller sub-canopy species such as toro.

\section{Advantages of the frass drop method}

Although the labour required to extract frass from litter samples is high compared to the time required to extract information from weta motels or tracking tunnels, the frass drop method has several advantages over these other methods. For tree weta, no time other than the collection period itself is required after litter tray installation, whereas an establishment period of 1-3 years is needed for tree weta occupation to stabilise after motel installation (Trewick \& Morgan-Richards 2000; Spurr \& Berben 2004; Bleakley et al. 2006; Ruscoe et al. 2013). Tree weta change their activity patterns following rat control by increasing their time spent outside of refuges and near the ground (Rufaut \& Gibbs 2003). This is likely to impact the efficacy of tracking tunnels and weta motels. Frass drop counts may be less susceptible to any biases arising from such behaviour changes because weta do not interact with the collection device and their activity is detected at a wide range of above-ground heights. Frass collection is also a non-lethal method that integrates long-term day-to-day variation in invertebrate activity, while weta motels and tracking tunnels 
are usually measured over one to three days. Lastly, a greater range of arboreal invertebrates than are typically recorded in weta motels and tracking tunnels, including more than the three measured here, can be monitored simultaneously by the frass drop method.

The frass drop method provides an affordable and practical means to assess the relative abundance of some large New Zealand arboreal invertebrates. The method has several advantages over other low-cost methods that are currently used, but requires further validation of the relationship between frass drop and invertebrate abundance before it can be recommended for routine use in New Zealand forests. The information provided by this study will help wildlife researchers and managers design and implement frass-drop-collection studies and programs for monitoring arboreal invertebrates in native New Zealand forests.

\section{Acknowledgements}

We thank the many people involved in field sample collection including C. Thomson, C. Brausch, G. Morris, K. McCarthy, M. Bridge, M. Perry, M. Coleman, N. Fea, R. Carran, R. Mapp and S. Hough. Comments by R. Pech, A. Glen, C. Watts, D. Tompkins, L. Kearns and C. Ernst greatly improved the manuscript. This work was funded by Core funding for Crown Research Institutes from the Ministry of Business, Innovation and Employment's Science and Innovation Group (contract CO9X0909).

\section{References}

Bell BD 1978. The Big South Cape Islands rat irruption. In: Dingwall PR, Atkinson IAE, Hay C eds The ecology and control of rodents in New Zealand nature reserves. Department of Lands and Survey Information Series 4. Wellington, Department of Lands and Survey Information. Pp. 33-40.

Best LW 1969. Food of the roof-rat, Rattus rattus (L), in two forest areas of New Zealand. New Zealand Journal of Science 12: 258-267.

Blackwell GL 2000. An investigation of the factors regulating motel mouse (Mus musculus) and ship rat (Rattus rattus) population dynamics in forest ecosystems at Lake Waikaremoana, New Zealand. PhD thesis, Massey University, Palmerston North, New Zealand.

Bleakley C, Stringer I, Robertson A, Hedderley D 2006. Design and use of artificial refuges for monitoring adult tree weta, Hemideina crassidens and $H$. thoracica. DOC Research and Development Series 233. Wellington, Department of Conservation. 37 p.

Cowan PE 2005. Brushtail possum. In: King CM ed The handbook of New Zealand mammals. 2nd edition. MelbourneAustralia, Oxford University Press. Pp. 56-80.

Daniel MJ 1973. Seasonal diet of the ship rat (Rattus $r$. rattus) in lowland forest in New Zealand. Proceedings of the New Zealand Ecological Society 20: 21-30.

Engeman R 2005. Indexing principles and a widely applicable paradigm for indexing animal populations. Wildlife Research 32: 203-210.

Eymann J, DegreefJ, Haser CH, Spiegel V2010. Manual on field recording techniques and protocols for all taxa biodiversity inventories and monitoring. Abc Taxa 8: 1-653.
Fischbacher M, Naef-Daenzer B, Naef-Daenzer L 1998. Estimating caterpillar density on trees by collection of frass droppings. Ardea 86: 121-129.

Foster S, King C, Patty B, Miller S 2011. Tree-climbing capabilities of Norway and ship rats. New Zealand Journal of Zoology 38: 285-296.

Innes J 2005. Ship rat. In: King CM ed The handbook of New Zealand mammals. 2nd edition. Melbourne, Australia, Oxford University Press. Pp. 187-203.

Kamata N, Igarashi Y 1994. Problem in estimating the density of larval beech caterpillar, Quadricalifera punctatella (Motschulsky) (Lep, Notodontidae), using frass drop by modification of the Southwood-Jepson method. Journal of Applied Entomology 118: 92-99.

Kamata N, Igarashi Y, Yanbe T, Igarashi M 1994. Estimating the density of beech caterpillar, Quadricalifera punctatella, by frass drop samples. Japan Agricultural Research Quarterly 28: 217-233.

King CM, Murphy EC 2005. Stoat. In: King CM ed The handbook of New Zealand mammals. 2nd edition. Melbourne, Australia, Oxford University Press. Pp. 261-287.

Liebhold AM, Elkinton JS 1988a. Techniques for estimating the density of late-instar gypsy moth, Lymantria dispar (Lepidoptera: Lymantriidae), populations using frass drop and frass production measurements. Environmental entomology 17: 381-384.

Liebhold AM, Elkinton JS 1988b. Estimating the density of larval gypsy moth, Lymantria dispar (Lepidoptera: Lymantriidae), using frass drop and frass production measures: sources of variation and sample size. Environmental Entomology 17: 385-390.

Miller CJ, Miller TK 1995. Population dynamics and diet of rodents on Rangitoto Island, New Zealand, including the effect of a 1080 poison operation. New Zealand Journal of Ecology 19: 19-27.

Mizutani M, Hijii N 2001. Mensuration of frass drop for evaluating arthropod biomass in canopies: a comparison among Cryptomeria japonica, Larix kaempferi, and deciduous broad-leaved trees. Forest Ecology and Management 154: 327-335.

Morris RF 1949. Frass-drop measurement in studies of the European spruce sawfly. University of Michigan School of Forest Conservation Bulletin 12. 58 p.

Morris RF 1960. Sampling insect populations. Annual Review of Entomology 5: 243-264.

Nakagawa S, Schielzeth H 2010. Repeatability for Gaussian and non-Gaussian data: a practical guide for biologists. Biological Reviews 85: 935-956.

NIWA 2014. Climate data and activity. Auckland, New Zealand, National Institute of Water and Atmospheric Research. www.niwa.co.nz/education-and-training/ schools/resources/climate/ (accessed 14/10/14).

R Development Core Team 2015 R: A language and environment for statistical computing. Version 3.2.1. Vienna, Austria, R Foundation for Statistical Computing.

RufautCG, Gibbs GW 2003. Response of a tree weta population (Hemideina crassidens) after eradication of the Polynesian rat from a New Zealand Island. Restoration Ecology 11: 13-19.

Ruscoe WA, Sweetapple PJ, Perry M, Duncan RP 2013. Effect of spatially extensive control of invasive rats on abundance of native invertebrates in mainland New Zealand forests. Conservation Biology 27: 74-82. 
Southwood TRE 1978. Ecological Methods. 2nd edn. London, Capman \& Hall. 524 p.

Spurr EB, Berben PH 2004. Assessment of non-target impact of 1080-poisoning for vertebrate pest control on weta (Orthoptera: Anostostomatidae and Rhaphidophoridae) and other invertebrates in artificial refuges. New Zealand Journal of Ecology 28: 63-72.

St Clair JJH 2011. The impacts of invasive rodents on island invertebrates. Biological Conservation 144: 68-81.

Stork NE, Adis J, Didham RK 1997. Canopy Arthropods. London, Chapman \& Hall. 567 p.

Suckling DM, Burnip GM, Hackett J, Daly JC 2006. Frass sampling and baiting indicate European earwig (Forficula auricularia) foraging in orchards. Journal of Applied Entomology 130: 263-267.

Towns DR 2009. Eradications as reverse invasions: lessons from Pacific rat (Rattus exulans) removals on New Zealand islands. Biological Invasions 11: 1719-1733.

Editorial board member: Brent Sinclair

Received 7 October 2015; accepted 8 March 2016
Trewick SA, Morgan-Richards M 1995. On the distribution of tree weta in the North Island, New Zealand. Journal of the Royal Society of New Zealand 25: 485-493.

Trewick SA, Morgan-Richards M2000. Artificial weta roots: a technique for ecological study and population monitoring of tree weta (Hemideina) and other invertebrates. New Zealand Journal of Ecology 24: 201-208.

Veltman C 2000. Do native wildlife benefit from possum control? In: Montague TL ed The brushtail possum: biology, impact and management of an introduced marsupial. Lincoln, New Zealand, Manaaki Whenua Press. Pp. 241-250.

Watts CH, Thornburrow D, Green CJ, Warren R 2008. Tracking tunnels: a novel method for detecting a threatened New Zealand giant weta (Orthoptera: Anostomatidae). New Zealand Journal of Ecology 32: 92-97.

Watts CH, Armstrong DP, Innes J, Thornburrow D 2011. Dramatic increases in weta (Orthoptera) following mammal eradication on Maungatautari - evidence from pitfall and tracking tunnels. New Zealand Journal of Ecology 35: 261-272. 